Research Article

\title{
Tetanus Toxoid Immunization Status and Associated Factors among Mothers in Damboya Woreda, Kembata Tembaro Zone, SNNP, Ethiopia
}

\author{
Muluken Dubale Mamoro ${ }^{1}$ and Lolemo Kelbiso Hanfore iD $^{2}$ \\ ${ }^{1}$ Damboya Woreda, Curative and Rehabilitative Core Process Coordinator of the Health Office, SNNP, Ethiopia \\ ${ }^{2}$ Wolaita Sodo University, College of Health Sciences and Medicine, Department of Nursing, Wolaita Sodo, Ethiopia \\ Correspondence should be addressed to Lolemo Kelbiso Hanfore; lolemo2001@gmail.com
}

Received 16 May 2018; Revised 8 September 2018; Accepted 13 September 2018; Published 22 November 2018

Academic Editor: José María Huerta

Copyright (c) 2018 Muluken Dubale Mamoro and Lolemo Kelbiso Hanfore. This is an open access article distributed under the Creative Commons Attribution License, which permits unrestricted use, distribution, and reproduction in any medium, provided the original work is properly cited.

Background. Tetanus toxoid immunization is one of the proven strategies for eliminating maternal and neonatal tetanus. According to Ethiopian Demographic Health Survey of 2016, only 49\% of mothers received two tetanus toxoid (TT) injections during their last pregnancy which is below the World Health Organization and Ethiopia Ministry of Health recommendation. Therefore, the aim of this study was to determine the status of TT immunization among mothers in Damboya Woreda, South Ethiopia. Method. A community-based cross-sectional study was conducted from March 1 to 26, 2017, in Damboya Woreda. A total of 837 mothers who had given birth in the last 12 months were included in the study. The simple random sampling method was used to select the study participants, and data were collected through an interview using a structured questionnaire. Data were entered into Epi data software version 3.1 and exported to SPSS version 22 for further analysis. Logistic regression was used to identify independent predictors of the immunization status of mothers at a $5 \%$ significance level. Result. The finding of this study revealed that $607(72.5 \%)$ mothers were protected at birth against tetanus. Age of mother who attended elementary school, husbands' education status, visited by HEW's at home, making joint health decision with husband, use of modern family planning method, number of antenatal care visit, and time to reach the nearest health facility were independent predictors of TT immunization status among the mothers. Conclusion. Significant proportions of the mothers were not taken at least two doses of TT vaccine which is a minimum dose to prevent maternal or neonatal tetanus. Even though most mothers had access for TT immunization service, they were not immunized with protective doses of TT vaccine.

\section{Introduction}

Tetanus vaccine is an inactivated toxin (toxoid) that was produced in 1924 and became commercially available in 1938 [1]. The immunization of pregnant women or women of childbearing age with two doses of TT vaccination may reduce the neonatal tetanus mortality by $94 \%$ [2].

Globally, an estimated 3.3 million neonatal deaths occur each year and about 9,000 babies who were within the first 28 days of life die each day. From this death, NT shares a high number [3], and in 2015, WHO estimate 34,019 newborns died from NT [4].

A study done in Ghana revealed that $71 \%$ of mothers had received two doses of TT injection during pregnancy or protected at birth [5], and another study in Kenya showed $63 \%$ mothers had received TT2+ doses of injection during their last child pregnancy [6].

Concerning maternal age, a study conducted in India showed that mothers whose age is from 20 to 30 years and above 30 years were more likely to receive two doses of TT injection than mothers whose age is less than 20 years [7]. A similar study conducted in Kenya revealed that age group between 20 and 29 years was significantly associated with TT immunization status of mothers [8].

Studies revealed that mothers who had higher, secondary, and primary education were more likely to receive two or above doses of TT injections than mothers with no formal education $[2,7,9]$, and concerning husband educational 
status, mothers whose husbands had primary and secondary and above education showed significant positive association with two or above doses of TT injections [10].

Regarding the occupational status of husband, mothers whose husbands are government employee were $75 \%$ more immunized than mothers whose husbands are other laborers and mothers who were government employee were $68.4 \%$ more immunized than mothers who were housewives [10].

Another cross-sectional study in Kenya revealed that mothers who make joint health decision with husband for their health issue were more likely to receive two doses of TT injection [11], and regarding wealth quintiles, mothers from richest family were more likely to have TT vaccination when compared to mothers from poorest family [6].

A study done in Lahore-Pakistan showed from the study participants $15 \%$ of mothers stated that TT vaccine was useless, $40 \%$ reasoned vaccination centers at a distant place, and 5\% believed that it was harmful to the fetus [6]. A similar study conducted in Peshawar, Pakistan, showed that lack of awareness, distance, fear of side effect, and fear of sterility were reasons for not taking TT vaccination [10].

Cross-sectional studies conducted in Cameroon showed that knowledge and attitude of mothers were significantly associated with TT immunization status of mothers and mothers with higher knowledge had more potential than those with lower knowledge to get the complete TT immunization and mothers with a positive attitude for TT vaccination were more likely to obtain protective doses of TT injection compared to those with the negative attitude [12]. A similar study conducted in Pakistan showed that mothers' knowledge on TT vaccination had a significant and positive impact on TT immunization status and women having information about TT vaccination were more likely to receive TT vaccination as compared to their counterparts of having no information [13].

Studies carried out in Pakistan and Kenya revealed that mothers' antenatal care had significant and positive impact on TT immunization status of mothers and frequencies of health facility visit were significantly associated with TT immunization status $[10,11]$, and other cross-sectional studies in Kenya and Bangladesh showed that use of modern family planning method was significantly associated with TT immunization status $[7,11]$.

Cross-sectional study in Vientiane showed that parity, multipara mothers were more likely to use TT than primipara mothers [14], and another study in Bangladesh revealed that mothers who want more children in future were more likely to receive two or more doses of TT injection congruent parts [7].

A study done in Kenya showed that there was significant association between health information to the mothers and tetanus toxoid immunization coverage [8], and concerning the source for TT vaccination information, $33.6 \%$ participants heard from a health worker, $30.9 \%$ heard from school lessons, $13.8 \%$ heard from the mass media, $8.2 \%$ heard from the mass media and family members, and the remaining $6.2 \%$ heard from family members alone [15].

A study done in Ethiopia showed that nearly $74 \%$ of mothers had received at least two doses of TT injection [13].
According to 2011 DHS of Ethiopia, education and household wealth index have a positive effect on whether women receive TT injections. For example, 62 percent of mothers with more than secondary education received at least two injections during their last pregnancy compared with 29 percent of mothers with no education. Also, 52\% of mothers in the highest wealth quintile received at least two doses of TT injection compared with 24 percent of mothers in the lowest wealth quintile [16], and according to 2016 EDHS, the proportion of mothers who protected against tetanus at last birth were $49 \%$ which was similar to that reported in the 2011 EDHS which was 48\% [17].

Ethiopia has the highest neonatal tetanus morbidity and mortality rates in the world due to low TT immunization coverage coupled with the high amount of deliveries taking place at home in unsanitary conditions [18]. However, there has been no study conducted so far to assess factors associated with TT immunization status with the current global push for MNTE mothers with TT vaccination which is one of the proven strategies for eliminating MNT, towards reaching the MNT elimination goal. Thus, identifying factors influencing mothers from TT immunization is critical for countries like Ethiopia since institutional delivery is very low.

\section{Method and Materials}

2.1. The Study Area, Period, and Study Design. A communitybased cross-sectional study was conducted from March 1 to 26, 2017, in Damboya Woreda, Kembata Tembaro Zone, South Ethiopia. Damboya is $16 \mathrm{~km}, 110 \mathrm{~km}$, and $350 \mathrm{~km}$ away from zonal, regional, and federal head offices, respectively. The Woreda has 3 urban and 17 rural kebeles with the projected population of 105841 of whom 51862 (49\%) were males. The total childbearing age women were 24,666 , and estimated pregnancy was 3662 in the Woreda which constituted $3.5 \%$ of the population. According to Woreda Health Office Annual Report, the physical health services coverage was estimated to be $100 \%$. There are four health centers and 19 health posts which are all government-owned and 2 medium clinics, 2 drug stores, and 1 diagnostic private-owned facility.

\subsection{Population}

2.2.1. Source Population. All mothers who are in childbearing age were the source population in Damboya Woreda.

2.2.2. Study Population. Sampled mothers who had given birth in the last 12 months in the selected kebeles during the data collection period were the study population.

2.3. Inclusion and Exclusion Criteria. Mothers who live in the Woreda for at least 6 months were included, and mothers who were critically ill or unable to respond were excluded from the study. 


\section{Sample Size Determination and Sampling Techniques}

3.1. Sample Size Determination. The sample sizes were calculated for both single and double population proportion by manual for single population and using Epi InfoTM7 version 7.1 statistical functions for double population proportion.

(a) For single population proportion, the following parameters were considered:

$P=$ proportion of mothers received at least two TT doses $=50.9 \%[17]$

$D=$ margin of error $=0.05$ with $95 \%$ confidence interval

$Z=1.96$ (level of significance)

$n=(\mathrm{z} \alpha / 2) 2 p \quad(1-p) / \mathrm{d} 2=(1.96) 2.509 \quad(1-0.509) /$

(0.05) $2=384$

(b) For double population proportion calculated using Epi InfoTM7 version 7.1 Statcalc function.

Parameters used in double population proportion formula were as follows:

$\mathrm{P} 1=\%$ of outcome among the exposed group

$\mathrm{P} 2=\%$ of outcome among the unexposed group

Confidence interval $=95 \%$

The formula that yields the highest number was taken to calculate the final sample size. Considering the design effect of 2 and 10\% nonresponse rate, the final sample size was 845 (Table 1).

3.2. Sampling Techniques. Two-stage stratified sampling technique was employed in the study. Total of 20 kebeles found in the Woreda were stratified into urban and rural kebeles. There were 3 urban and 17 rural kebeles. Then, 2 urban and 11 rural kebeles were selected by simple random sampling method. Registration of mothers who had given birth in the last 12 months was made from a family folder and delivery registration book at each health post level before the actual data collection in all the selected kebeles to create sampling frame. Then each household was given consecutive corresponding house number according to the sampling frame. If there is more than one mother in the household with a history of birth in the last 12 months, a mother was selected by lottery method. The number of study participants from each selected kebele was determined based on the number of childbearing age mothers in each kebele. Finally, a simple random sampling technique was employed to select the study participants.

\section{Variables}

4.1. Dependent Variable. TT immunization status.

4.2. Independent Variables. Sociodemographic characteristics: age, marital status, religion, ethnicity, educational status of the mother, educational status of husband, wealth index of household, mother occupation, husband occupation, use of mass media, place of residence, and making a joint decision with husband for a health issue. Reproductive factors: parity and pregnancy plan. Behavioral factors: knowledge, attitude, ANC visit, and use of modern family planning method. Health service-related factors: accessibility of the service, health extension worker home visit, and getting information for TT vaccination from health professionals.

4.3. Operational Definitions. Immunization status: when mothers had received $<2$ TT dose (not protected at birth) or had received $\geq 2$ TT doses (protected at birth).

Protected at birth $(\mathrm{PAB})$ : if the mother had received documented or not, two or more doses during current pregnancy or at least two TT doses prior to the current pregnancy of which the last dose was $<3$ years before the birth; or three doses within the 5 years before the current pregnancy; or four doses with the last dose $<10$ years before the pregnancy or receiving five doses or more before the current pregnancy.

4.4. Instruments. Data were collected by using structured questionnaire adapted from WHO, EDHS, and different kinds of literature and adapted to the local context. The structured questionnaire was prepared in English, translated to Amharic and Kembatissa, and back-translated to the English language by independent translators.

4.5. Data Collection Process. Participants were interviewed in their household using translated structured questionnaire. Data collection was carried out by 13 trained diploma nurses who speak Amharic and Kembatissa fluently with 13 local guides to simplify the data collection process. Information on socioeconomic and demographic characteristics, reproductive characteristics, health service-related factors, and behavioral factors was collected with immunization history of mothers which was collected from vaccination cards, mother's verbal report, or both.

4.6. Data Processing and Analysis. Data were checked, cleaned, and entered into Epi data software version 3.1 and then exported to SPSS version 22 for analysis. Descriptive statistics were used to summarize the data. Bivariate logistic regression analysis was done to identify candidates for multivariable logistic regression analysis. All explanatory variables with a $p$ value of less than 0.2 in bivariate logistic regression analysis were included in the initial logistic model of multivariable logistic regression analysis to identify independent predictors. Then crude and adjusted odds ratio together with their corresponding 95\% confidence intervals were computed. A $p$ value $<0.05$ was considered as statistically significant in this study.

4.7. Data Quality Assurance. To assure the quality of data, the questionnaire was translated to Amharic and Kembatissa languages and back-translated into English to see the 
TABLE 1: List of exposure variables to calculate sample size for associated factors.

\begin{tabular}{|c|c|c|c|c|c|c|c|}
\hline Exposure variable & $\begin{array}{l}\% \text { of outcome among } \\
\text { the unexposed group }\end{array}$ & $\begin{array}{l}\% \text { of outcome among } \\
\text { the exposed group }\end{array}$ & $\begin{array}{c}\text { Odds } \\
\text { ratio (OR) }\end{array}$ & $\begin{array}{l}\text { Confidence } \\
\text { interval (\%) }\end{array}$ & Power & $\begin{array}{l}\text { Sample } \\
\text { size }(n)\end{array}$ & References \\
\hline $\begin{array}{l}\text { Maternal education } \\
\text { (secondary and above) }\end{array}$ & 41 & 83 & & 95 & 80 & 50 & [11] \\
\hline ANC visit (2 and above) & 45.3 & 81.9 & 2.14 & 95 & 80 & 64 & {$[14]$} \\
\hline
\end{tabular}

consistency. Both the interviewers and supervisors were trained for two days on the objectives, data collection, and interviewing approaches. A pretest was conducted in 5\% of the samples of both urban and rural kebeles. The reliability test was conducted and the value of Cronbach's alpha $>0.7$ items is considered as reliable for study questionnaire. Completeness, consistency, and applicability of the instruments were ratified accordingly. At the time of data collection, filled questionnaires were checked for completeness and consistency of information by the PI and supervisor on daily basis.

\section{Results}

5.1. Socioeconomic and Demographic Characteristics. Of the total 845 mothers planned to be included in the study, 837 mothers who had given birth in the last 12 months before the survey were actually participated in the study by giving $99 \%$ response rate.

Based on residence, 710 (84.8\%) rural and 510 (60.1\%) of the mothers age falls in the range of 21-30 years with the mean age of $28( \pm 5.362)$ years. Seven hundred ninety-one (94.5\%) were Kembata by ethnicity, 699 (83.5\%) were protestant religion followers, and 822 (98.2\%) were married. Regarding educational status, 384 (45.9\%) mothers and 517 $(61.8 \%)$ mother's husband have no formal education, respectively, and 788 (94\%) mothers were housewife by occupation; likewise, $79.9 \%$ husbands were farmers. Regarding family size, $524(62.5 \%)$ mothers had less than or equal to five family members, and concerning mass media, $35.5 \%$ and $4.4 \%$ mothers were an owner of radio and television, respectively (Table 2).

\subsection{Reason for Not Starting or Completing TT Vaccination.} As mothers were asked for the reasons why they either do not complete or started tetanus toxoid vaccination, the response was not knowing about taking next dose of TT vaccine $(263,53 \%)$, lack of motivation to go for next doses $(159,21 \%)$, and no problem faced related to being not immunized $(60,8.1 \%)$ were the main reasons for not completing and not knowing about TT vaccination (40, $43.5 \%$ ) was main reasons for not starting TT vaccination (Figures 1 and 2).

5.3. Reproductive Characteristics of Mothers. Five hundred four $(60.2 \%)$ women gave birth to $2-4$ children in their life. The majority (86.9\%) of mothers had planned to have a child for last pregnancy and $87.7 \%$ mothers have future fertility plan (Table 3).
5.4. Behavioral Factors on Tetanus Toxoid Immunization Status. Concerning behavioral factors, 784 (93\%) mothers attended at least one antenatal care visit, 566 (67.6\%) mothers used modern family planning method, and 320 $(38.2 \%)$ had poor knowledge with a mean score of $7.7( \pm 2.3)$ (Table 4).

5.5. Health Service-Related Factors on Tetanus Toxoid Immunization Status. Seven hundred seven (84.5\%) mothers had obtained TT vaccine information from health professionals. For accessibility of TT vaccination services, 814 (97.3\%) mothers said TT vaccination was provided by facility nearby and 767 (91.6\%) of them walk less than 1 hour on foot to reach the nearest health facility. 448 (53.5\%) mothers had vaccination card, while the rest 389 (46.5\%) did not have during survey time. Majority of 614 (73.4\%) mothers were visited by health extension package workers in their home in last pregnancy time (Table 5) and 463 (55.3\%) health extension package workers and 165 (23\%) health workers were their source of information (Table 6).

5.6. Immunization Status of Mothers. Based on mother's vaccination card and oral history, 607 (72.5\%) mothers were protected against tetanus at last birth. For 448 (53.5\%) mothers, the source for their tetanus toxoid immunization status was card plus oral history, while for the rest 389 $(46.5 \%)$ the source was oral history only (Figure 3 ).

5.7. Factors Associated with TT Immunization Status of Mothers. Variables in the bivariate analysis with a $p$ value $<0.2$ were included in the multivariable analysis to determine independent predictors of TT immunization status.

Age of mother, mothers' educational status, husbands' educational status, making joint decision with husband for their health issue, health extension worker home visiting, use of modern family planning method, number of antenatal care visit, and time to reach the nearest health facility were independent predictors of TT immunization status of mothers with $p$ value $<0.05$ (Table 5).

\section{Discussion}

In this study, immunization status was assessed using the availability of vaccination card and maternal recall (oral history). Based on both immunization card and oral history, $607(72.5 \%)$ mothers were protected against tetanus at their last birth. This finding is similar to a study done in Ethiopia and Ghana $[4,9]$ but higher than the proportion reported in 
TABle 2: Socioeconomic and demographic characteristics of mothers, in Damboya Woreda, South Ethiopia, March 2017 $(n=837)$.

\begin{tabular}{|c|c|c|}
\hline Variables & Number of mothers & Percentage \\
\hline $\begin{array}{l}\text { Residence } \\
\text { Rural } \\
\text { Urban }\end{array}$ & $\begin{array}{l}709 \\
128\end{array}$ & $\begin{array}{l}84.8 \\
15.2\end{array}$ \\
\hline $\begin{array}{l}\text { Age } \\
\leq 20 \text { years } \\
21-30 \text { years } \\
>30 \text { years } \\
\end{array}$ & $\begin{array}{l}113 \\
510 \\
214 \\
\end{array}$ & $\begin{array}{l}13.5 \\
60.9 \\
25.6\end{array}$ \\
\hline $\begin{array}{l}\text { Ethnicity } \\
\text { Kembata } \\
\text { Hadiya } \\
\text { Others }\end{array}$ & $\begin{array}{c}791 \\
26 \\
20\end{array}$ & $\begin{array}{c}94.5 \\
3.1 \\
2.4\end{array}$ \\
\hline $\begin{array}{l}\text { Religion } \\
\text { Protestant } \\
\text { Muslim } \\
\text { Orthodox } \\
\text { Catholic } \\
\end{array}$ & $\begin{array}{c}699 \\
76 \\
46 \\
16 \\
\end{array}$ & $\begin{array}{c}83.5 \\
9.1 \\
5.5 \\
1.9\end{array}$ \\
\hline $\begin{array}{l}\text { Marital status } \\
\text { Married } \\
\text { Others }\end{array}$ & $\begin{array}{c}822 \\
15\end{array}$ & $\begin{array}{c}98.2 \\
1.8\end{array}$ \\
\hline $\begin{array}{l}\text { Mother educational status } \\
\text { No formal education } \\
\text { Elementary school } \\
\text { Secondary and above }\end{array}$ & $\begin{array}{c}384 \\
377 \\
76 \\
\end{array}$ & $\begin{array}{c}45.9 \\
45 \\
9.1 \\
\end{array}$ \\
\hline $\begin{array}{l}\text { Husband educational status } \\
\text { No formal education } \\
\text { Elementary school } \\
\text { Secondary and above }\end{array}$ & $\begin{array}{c}517 \\
265 \\
55 \\
\end{array}$ & $\begin{array}{c}61.8 \\
31.7 \\
6.5 \\
\end{array}$ \\
\hline $\begin{array}{l}\text { Mother occupational status } \\
\text { Housewife } \\
\text { Merchant } \\
\text { Others }\end{array}$ & $\begin{array}{c}788 \\
22 \\
27 \\
\end{array}$ & $\begin{array}{c}94.2 \\
2.6 \\
3.2 \\
\end{array}$ \\
\hline $\begin{array}{l}\text { Husband occupational status } \\
\text { Farmer } \\
\text { Daily laborer } \\
\text { Government employee } \\
\text { Merchant } \\
\text { Others }\end{array}$ & $\begin{array}{c}669 \\
91 \\
37 \\
31 \\
9\end{array}$ & $\begin{array}{c}79.9 \\
10.9 \\
4.4 \\
3.7 \\
1.1\end{array}$ \\
\hline $\begin{array}{l}\text { Wealth index of household } \\
\text { Lowest } \\
\text { Second } \\
\text { Middle } \\
\text { Fourth } \\
\text { Highest }\end{array}$ & $\begin{array}{l}168 \\
167 \\
167 \\
168 \\
167\end{array}$ & $\begin{array}{l}20 \\
20 \\
20 \\
20 \\
20\end{array}$ \\
\hline $\begin{array}{l}\text { Household size } \\
\text { Less than or equal to } 5 \\
\text { Greater than } 5\end{array}$ & $\begin{array}{l}524 \\
313\end{array}$ & $\begin{array}{l}62.5 \\
37.5\end{array}$ \\
\hline $\begin{array}{l}\text { Having radio } \\
\text { Yes } \\
\text { No }\end{array}$ & $\begin{array}{l}295 \\
542\end{array}$ & $\begin{array}{l}35.5 \\
64.5\end{array}$ \\
\hline $\begin{array}{l}\text { Having television } \\
\text { Yes } \\
\text { No }\end{array}$ & $\begin{array}{c}37 \\
800\end{array}$ & $\begin{array}{c}4.4 \\
95.6\end{array}$ \\
\hline $\begin{array}{l}\text { Making a joint decision with } \\
\text { Yes } \\
\text { No }\end{array}$ & $\begin{array}{c}\text { husband about the } 1 \\
680 \\
157\end{array}$ & $\begin{array}{r}\text { th issue } \\
81.25 \\
18.75\end{array}$ \\
\hline
\end{tabular}

2016 EDHS report which was $49 \%$ and 50.9\% for national and SNNPR, respectively [11]. This difference might be due to hard to reach areas included in EDHS report and the additional health center construction in Damboya Woreda that gives an extra opportunity for TT vaccination.

This study showed that the major reasons for incomplete TT vaccination were as follows: mother not knowing about taking the next dose of TT vaccination, lack of motivation to receive the next dose, and provider did not tell me during facility visit while not knowing about TT vaccination, services area too far, and fear of side effect, which is in line with the studies conducted in Kenya and Pakistan $[7,8]$. This implies that utilization of TT vaccination service is dependent on mother's understanding of its importance and will be improved by conducting regular and focused education and communication activities on the need for vaccination, as well as interpersonal communication and negotiation on the need for subsequent doses of vaccine.

Also, this study revealed that mothers whose age is between 21 and 30 and $>30$ years were 3.36 and 9.69 times more likely to receive two doses of TT injection than mothers whose age is $\leq 20$ years, respectively. This finding is similar to study findings in Kenya, Vientiane, and India $[6,8,14]$. This is probably because of this age group actively participated in different health-related issues and their age maturity concerning marriage in taking responsibility for child health care. In addition, this age group may have past exposure which gave them practical knowledge about healthcare services to themselves and their children.

Concerning mothers' educational status, mothers who attended elementary school were 3.72 times more likely to receive two doses of TT injection than mothers who have no formal education. This is similar to the study done in Ethiopia and Bangladesh [6, 10]. This may be due to easy access to information and knowledge of a mother on immunization services and because of the fact that education is likely to enhance confidence.

Mothers whose husband had elementary and secondary and above education were 1.84 and 4.13 times more likely to receive two doses of TT injection, respectively, compared to mothers whose husband had no formal education. This finding is in line with the study done in Asia, Bangladesh, and Pakistan [2, 6, 7]. This may be due to the fact that educated husband has more exposure to different information sources concerning health issues and better level of understanding than the noneducated husband. Also, it is a general fact that education increases overall awareness including health and healthcare utilization of an individual.

The finding of this study revealed that mothers who attended 2-3 antenatal care visits were 4.68 times more likely to receive two doses of TT injection than mothers who attended less than two antenatal care visits. This finding is in line with the study conducted in Kenya, Vientiane, and Pakistan [7, 8, 14]. This might be because repeated health facility visit for ANC follow-up gives an opportunity for TT vaccine injection and provides an insight about NNT. 


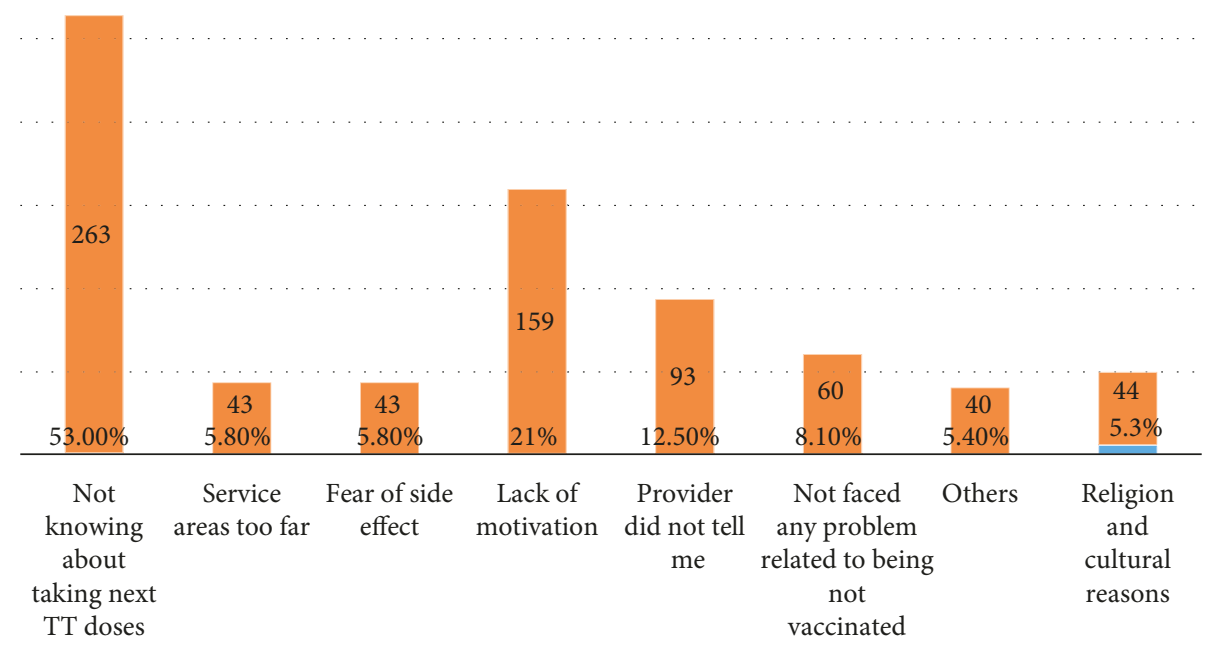

FIgURE 1: Reasons given by mothers for not completing TT vaccination in Damboya Woreda, South Ethiopia $(n=745)$.

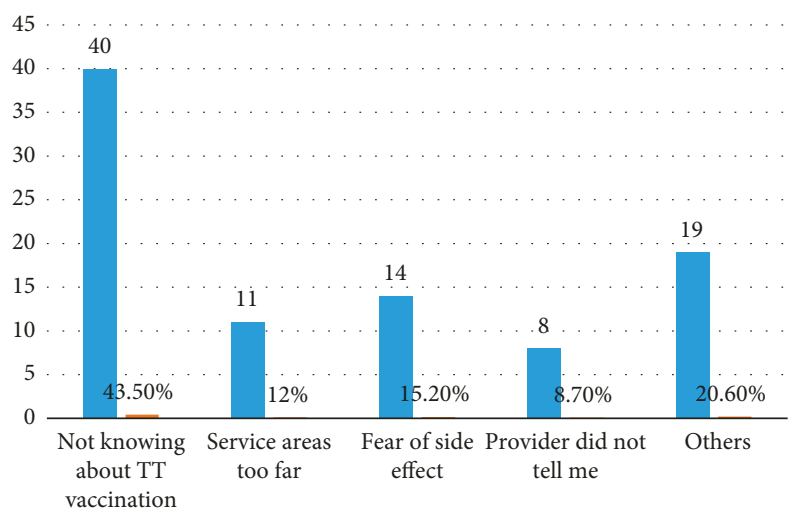

FIgURE 2: Reasons explained by mothers for not started TT vaccination in Damboya Woreda South Ethiopia $(n=92)$.

Table 3: Frequency of selected reproductive factors of mothers in Damboya Woreda, March $2017(N=837)$.

\begin{tabular}{|c|c|c|c|c|}
\hline Variables & Category & $\geq 2 \mathrm{TT}$ injections & $<2 \mathrm{TT}$ injections & COR $(95 \% \mathrm{CI})$ \\
\hline \multirow{3}{*}{ Parity } & 1 & $89(51.1 \%)$ & $85(48.9 \%)$ & 1 \\
\hline & $2-4$ & $389(77.2 \%)$ & $115(22.8 \%)$ & $3.23(2.25-4.64)$ \\
\hline & $\geq 5$ & $129(81.1 \%)$ & $30(18.9 \%)$ & $4.11(2.5-6.75)$ \\
\hline \multirow{2}{*}{ Future fertility plan } & Yes & $531(72.3 \%)$ & $203(27.7 \%)$ & $1.05(0.67-1.64)$ \\
\hline & No & $75(74.3 \%)$ & $26(25.7 \%)$ & 1 \\
\hline \multirow{2}{*}{ Plan for last childbirth } & Yes & $568(78.1 \%)$ & $159(21.9 \%)$ & $6.5(4.24-9.98)$ \\
\hline & No & $39(35.5 \%)$ & $71(64.5 \%)$ & 1 \\
\hline
\end{tabular}

Regarding distance from home to the nearest health facility, mothers who walk less than 1 hour to reach the nearest health facility were 2.93 times more likely to receive two doses of TT injection than mothers who walk greater than or equal to 1 hour to reach the nearest health facility. This finding is similar to the study done in Ethiopia [9]. And it indicates that as the time to reach health facility increases, the accepted rate of TT vaccine decreases and increasing accessibility of TT vaccination providing facility is good.

Mothers who use modern family planning method were 5.19 times more likely to receive two doses of TT injection as compared with those who do not use modern family planning. This is similar to the study conducted in Bangladesh [6]. It might be because health information is given in family planning service due to service integration.

Health extension worker home visit had positive impact on TT immunization status of a mother and a mother who was visited in her home during last pregnancy time by health extension worker was 7 times more likely to receive two doses of TT injection than a mother who did not visit. This is similar to the study done in Pakistan [7]. This might be because of the health education provided by health extension 
TABLE 4: Frequency of knowledge response of mothers on tetanus and TT vaccine, in Damboya Woreda, South Ethiopia, March 2017 $(N=837)$.

\begin{tabular}{|c|c|c|c|}
\hline Items & Categories & $\begin{array}{l}\text { Number } \\
\text { of mothers }\end{array}$ & Percentage \\
\hline \multirow{2}{*}{ Have you ever heard of about TT vaccination? } & Yes & 749 & 89.5 \\
\hline & No & 88 & 10.5 \\
\hline \multirow{2}{*}{ Lockjaw is the symptom of tetanus } & Yes & 603 & 72 \\
\hline & No & 224 & 28 \\
\hline \multirow{2}{*}{ Neck stiffness is a symptom of tetanus } & Yes & 620 & 74.1 \\
\hline & No & 117 & 25.9 \\
\hline \multirow{2}{*}{ Tetanus toxoid vaccine prevents tetanus } & Yes & 640 & 76.5 \\
\hline & No & 197 & 23.5 \\
\hline \multirow{2}{*}{ Tetanus toxoid vaccines serve as family planning } & Yes & 85 & 10.2 \\
\hline & No & 752 & 89.8 \\
\hline \multirow{2}{*}{$\begin{array}{l}\text { Tetanus toxoid vaccine gives protection for only } \\
\text { mothers }\end{array}$} & Yes & 109 & 13 \\
\hline & No & 628 & 87 \\
\hline \multirow{2}{*}{$\begin{array}{l}\text { Only one tetanus toxoid injection not gives } \\
\text { protection }\end{array}$} & Yes & 451 & 53.9 \\
\hline & No & 386 & 46.1 \\
\hline \multirow{2}{*}{ Five times TT injection give lifelong protection } & Yes & 567 & 67.7 \\
\hline & No & 270 & 37.3 \\
\hline \multirow{2}{*}{$\begin{array}{l}\text { Tetanus toxoid injection gives protection for both } \\
\text { mothers and baby from tetanus during birth }\end{array}$} & Yes & 643 & 76.8 \\
\hline & No & 194 & 23.2 \\
\hline
\end{tabular}

TABLE 5: Independent predictors of the tetanus toxoid immunization status of mothers in Damboya Woreda, South Ethiopia, March 2017 $(n=837)$.

\begin{tabular}{|c|c|c|c|c|}
\hline Variables & $\geq 2$ TT injections, $n(\%)$ & $<2$ TT injections, $n$ number (\%) & $\mathrm{AOR}$ & $95 \% \mathrm{CI}$ \\
\hline \multicolumn{5}{|l|}{ Age } \\
\hline$\leq 20$ years & $33(29.2 \%)$ & $80(70.8 \%)$ & 1 & \\
\hline $21-30$ years & $392(76.9 \%)$ & $118(23.1 \%)$ & 4.61 & $2.26-9.41^{*}$ \\
\hline$\geq 31$ year & $182(85 \%)$ & $32(15 \%)$ & 9.69 & $4.11-22.84^{*}$ \\
\hline \multicolumn{5}{|c|}{ Mother's educational status } \\
\hline No formal education & $207(53.9 \%)$ & $177(46.1 \%)$ & 1 & \\
\hline Elementary school & $334(88.6 \%)$ & $43(11.4 \%)$ & 3.42 & $2-5.86^{*}$ \\
\hline Secondary and above & $66(86.8 \%)$ & $10(13.2 \%)$ & 1.95 & $0.75-5.1^{*}$ \\
\hline \multicolumn{5}{|c|}{ Husband's educational status } \\
\hline No formal education & $333(64.4 \%)$ & $184(35.6 \%)$ & 1 & \\
\hline Elementary school & $227(85.7 \%)$ & $38(14.3 \%)$ & 1.84 & $1.03-3.28^{*}$ \\
\hline Secondary and above & $47(85.5 \%)$ & $8(14.5 \%)$ & 4.13 & $1.07-5.07^{*}$ \\
\hline \multicolumn{5}{|c|}{ Using modern family planning } \\
\hline Yes & $467(82.5 \%)$ & $99(17.5 \%)$ & 5.16 & $3.09-8.59^{*}$ \\
\hline No & $140(51.7 \%)$ & $131(48.3 \%)$ & 1 & \\
\hline \multicolumn{5}{|c|}{ Making a joint decision with the husband for health issues } \\
\hline Yes & $526(81.9 \%)$ & $116(18.1 \%)$ & 4.25 & $2.45-7.32^{*}$ \\
\hline No & $81(41.5 \%)$ & $114(58.5 \%)$ & 1 & \\
\hline \multicolumn{5}{|c|}{ Number of antenatal care visit } \\
\hline 1 & $50(38.8 \%)$ & $79(61.2 \%)$ & 1 & \\
\hline $2-3$ & $443(82 \%)$ & $97(18 \%)$ & 4.1 & $2.28-7.37^{*}$ \\
\hline$\geq 4$ & $103(89.6 \%)$ & $12(10.4 \%)$ & 10.09 & $3.63-28.1^{*}$ \\
\hline \multicolumn{5}{|c|}{ Planned for last child pregnancy } \\
\hline Yes & $568(78.1 \%)$ & $159(21.9 \%)$ & 0.07 & $0.94-3.85$ \\
\hline No & $39(35.5 \%)$ & $71(64.5 \%)$ & 1 & \\
\hline \multicolumn{5}{|c|}{ Health extension package worker home visit } \\
\hline Yes & $535(87.1 \%)$ & $79(12.9 \%)$ & 6.51 & $3.78-11.19^{*}$ \\
\hline No & $72(32.3 \%)$ & $151(67.7 \%)$ & 1 & \\
\hline \multicolumn{5}{|c|}{ Time to reach the nearest health facility from home on foot } \\
\hline$<1$ hour & $571(74.4 \%)$ & $196(25.6 \%)$ & 3.61 & $1.66-7.84^{*}$ \\
\hline$\geq 1$ hour & $36(51.4 \%)$ & $34(48.6 \%)$ & 1 & \\
\hline
\end{tabular}


TABLE 6: Frequency of health service-related factor on tetanus toxoid immunization status mothers, Damboya Woreda, South Ethiopia, March $2017(n=837)$.

\begin{tabular}{lccc}
\hline Variables $(N=837)$ & Category & Number & Percentage \\
\hline $\begin{array}{l}\text { Traveling time (in hour) } \\
\text { from home to the nearest } \\
\text { health facility }\end{array}$ & $\begin{array}{c}\text { Less than } \\
1 \text { hour } \\
\geq 1 \text { hour }\end{array}$ & 767 & 91.6 \\
\hline $\begin{array}{l}\text { Accessibility of TT } \\
\text { vaccination service }\end{array}$ & Yes & 814 & 8.4 \\
\hline $\begin{array}{l}\text { Getting TT vaccination } \\
\text { information from health }\end{array}$ & Yes & 23 & 2.7 \\
professionals & No & 130 & 84.5 \\
\hline $\begin{array}{l}\text { Visited by health extension } \\
\text { package worker at home }\end{array}$ & Yes & 614 & 15.5 \\
\hline
\end{tabular}

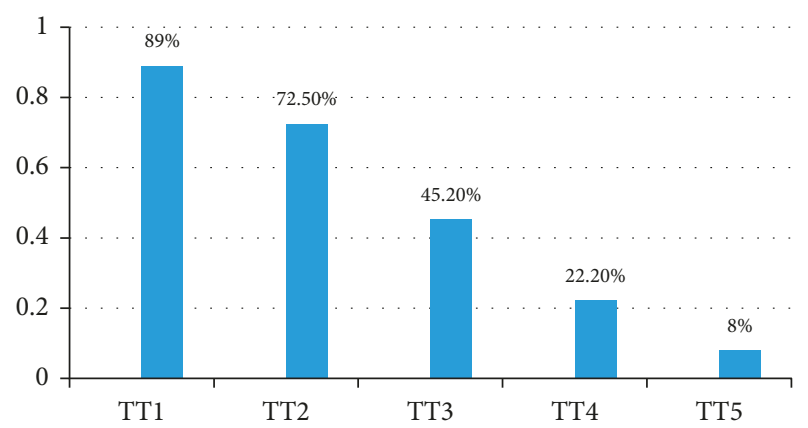

FIgURE 3: Level of tetanus toxoid vaccination coverage of mothers in Damboya Woreda, South Ethiopia, March $2017(n=745)$.

worker regarding the advantages of having TT vaccine during pregnancy and encouraging the mother to follow ANC as well.

Another predictor was making a joint decision with the husband about their health issue. In this study, a mother who made a joint decision about her health issue with her husband was 4 times more likely to receive two doses of TT injection than a mother who did not make a joint decision with her husband or made health decision alone. This finding is in line with the study done in Kenya [8]. This might be because a mother who made joint discussion with husband gets more confident and social support for the TT utilization and will have protective doses of TT vaccine.

6.1. Strength. Selection bias was minimized since it was community-based study with probability sampling technique. Gender match interview was conducted, and all the interviewers were familiar with the local language.

6.2. Limitation. Since immunization status was collected including self-report of mothers, this made it susceptible for recall bias. Institutional card or registration book review was not conducted to reduce recall bias.

\section{Conclusion and Recommendations}

In general, this study concluded that near to three-fourth of the mothers were protected against tetanus in last birth which was very low as to $\mathrm{WHO}$ recommendation for pregnant mothers (100\%). Also, the study found that mother's age, mother's educational status, husband educational status, use of modern family planning method, number of antenatal care visit, time to reach the nearest health facility, health extension home visit, and making joint decision with husband for their health issue were independent predictors for TT immunization status of mothers.

7.1. For Policy and Practice. Even though most mothers had access for TT immunization service, they were not immunized with protective doses of TT vaccine. So, at a community level joint decision making of mothers and husbands has to be strengthen to enhance health-seeking behavior and to increase the proportion of mothers protected at birth. It is also very important to work on health extension workers' commitment level improving programmed home visit services to pregnant mothers and strengthen mother's facility visit for ANC follow-up. Convenient outreach sites have to be established for those who are living distant from health facility to provide intensive public health education to fill the knowledge gap among the mothers.

7.2. For Future Research. This study provides an opportunity to assess TT immunization status and its predictors among mothers. In this regard, other studies should be conducted aiming at determining the proportion of tetanus toxoid immunization status of mothers by antibody testing to know the absolute proportion of mothers protected tetanus at birth.
Abbreviations
AOD: Adjusted odds ratio
CI: Confidence interval
COR: Crude odds ratio
EDHS: Ethiopian Demographic Health Survey
IRB: Institutional review board
MNET: Maternal and Neonatal Tetanus Elimination
NT: $\quad$ Neonatal tetanus
SPSS: Statistical Package for Social Sciences
TT: $\quad$ Tetanus toxoid
WHO: World Health Organization.

\section{Data Availability}

The data used to support the findings of this study are available from the corresponding author upon request.

\section{Ethical Approval}

The study was approved by the IRB (Institutional Review Board) of Jimma University. The official letter was written by School of Public Health, Jimma University, to the respective officials of the study area. Permission to undertake 
the study was obtained from every relevant authority in the Woreda. Informed verbal consent of the participants was secured explaining the aim of the study to each participant. The participants were interviewed in their household individually to maintain privacy. Confidentiality was ensured by not including names or other identifiers in the data collection tool. They were also informed that participation was on a voluntary basis and they can withdraw themselves at any time if they were not comfortable about the interview.

\section{Consent}

We agree to the terms and policies of the editorial office of the journal for publication.

\section{Conflicts of Interest}

The authors declared no conflicts of interest.

\section{Authors' Contributions}

MD made substantial contributions to conception and design, carried out the collection of data, was involved in general supervision of the research, analysis, and interpretation of data, and was involved in drafting the manuscript. LK made substantial contributions to conception and design, was responsible for acquisition of data involved in drafting the manuscript and revising it critically for important intellectual content, and gave final approval of the version to be published.

\section{Acknowledgments}

We would like to thank Jimma University for providing an ethical clearance for this research. We also thank the health managers and the participants who have been very cooperative during data collection.

\section{Supplementary Materials}

Table S1: bivariate analysis of socioeconomic and demographic characteristics of mothers on tetanus toxoid immunization status in Damboya Woreda, March 2017 $(n=837)$. Table S2: bivariate analysis of behavioral factors on the tetanus toxoid immunization status of mothers in Damboya Woreda, South Ethiopia, March $2017(n=837)$. Table S3: bivariate analysis of service-related factors on the tetanus toxoid immunization status of mothers, Damboya Woreda, South Ethiopia, March $2017(n=837)$. (Supplementary Materials)

\section{References}

[1] M. Anokye, J. A. Mensah, F. Frimpong, E. Aboagye, and N. Acheampong, "Immunization coverage of pregnant women with tetanus toxoid vaccine in dormaa east districtbrong adaro region, Ghana," Mathematical Theory and Modeling, vol. 4, no. 6, pp. 47-56, 2014.
[2] E. Rana Anglican and M. A. Raza, "Maternal health care: the case of tetanus toxoid vaccination," Asian Development Policy Review, vol. 1, no. 1, pp. 1-14, 2013.

[3] UNICEF, UNFPA, and WHO, Achieving and Sustaining Maternal and Neonatal Tetanus Elimination Strategic Plan 2012-2015, 2010.

[4] WHO, Maternal and Neonatal Tetanus Elimination the Initiative and Challenges Why Maternal and Neonatal Tetanus Elimination, WHO, Geneva, Switzerland, 2017.

[5] S. K. Diamenu, G. Bosnu, F. Abotsi et al., "Introducing protection at birth method of monitoring tetanus-diphtheria vaccination coverage of mothers in Ghana," International Journal of Vaccines and Immunization, vol. 1, no. 1, 2015.

[6] F. K. Hashmi, M. Islam, T. A. Khan, and M. K. Tipu, "Vaccination coverage of mothers during pregnancy with tetanus toxoid and infants after birth," Pakistan Journal of Pharmacy, vol. 24, no. 2, pp. 1-3, 2011.

[7] A. Singh, S. Pallikadavath, R. Ogollah, and W. Stones, "Maternal tetanus toxoid vaccination and neonatal mortality in Rural North India," PLoS One, vol. 7, no. 11, Article ID e48891, 2012.

[8] M. Naeem, M. Z. Khan, S. H. Abbas et al., "Coverage, and factors associated with TT vaccination among married women of reproductive age, Peshawar Pakistan," Journal of Ayub Medical College, vol. 22, no. 3, pp. 136-140, 2010.

[9] Z. T. Haile, I. R. Azulay Chertok, and A. K. Teweldeberhan, "Determinants of utilization of sufficient TT immunization during pregnancy: evidence from the Kenya demographic and health survey, 2008-2009," Journal of Community Health, vol. 38, no. 3, pp. 492-499, 2013.

[10] JSI, An Extended Programme on Immunization Coverage in Selected Ethiopia Zones a Baseline Survey for L10 kms Routine Immunization Improvement Initiative, JSI, Boston, MA, USA, 2015.

[11] C. S. Agency, Ethiopia Demographic and Health Survey Addis Ababa, Ethiopia ICF International, Calverton, MA, USA, 2011.

[12] C. S. Agency, Ethiopia Demographic and Health Survey Addis Ababa, Ethiopia ICF International, Calverton, MA, USA, 2016.

[13] EMO Health, National Expanding Programme of Immunization, EMO Health, Addis Ababa, Ethiopia, 2010.

[14] K. Masuno, D. Xaysomphoo, A. Phengsavanh, S. Douangmala, and C. Kuroiwa, "Scaling up interventions to eliminate neonatal tetanus: factors associated with the coverage of tetanus toxoid and clean deliveries among women in Vientiane, Lao PDR," Vaccine, vol. 27, no. 32, pp. 4284-4288, 2009.

[15] B. Alex-Hart and B. Okoh, "Awareness and status of tetanus toxoid vaccination among female undergraduate students in a Nigerian University," International Journal of Tropical Disease \& Health, vol. 7, no. 1, pp. 6-15, 2015.

[16] V. M. Ngachangong, M. G. Melanie, and E. N. Tufon, "Factors related to the escapement of reproductive age women from tetanus toxoid vaccination at the sub-divisional medicalized health center, Nkwen, Bamenda Cameron," Vedic Research International Cell Signaling, vol. 2, no. 1, p. 22, 2014.

[17] A. Debbie, A. Amdu, A. Alamneh et al., "A clinical profile of tetanus patients attended at felegehiwot referral hospital, northwest ethiopia: a retrospective cross-sectional study," SpringerPlus, vol. 5, no. 1, p. 892, 2016.

[18] W. Maima, M. Ephantus, and E. A. Kabiru, "Utilization of antenatal TT immunization services among women in Bahati division, Naku country Kenya," International of innovative research and studies, vol. 3, no. 9, 2014. 


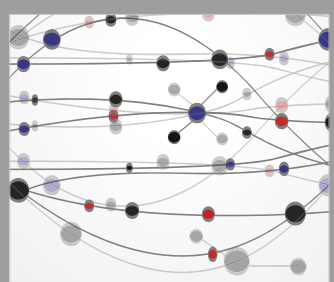

The Scientific World Journal
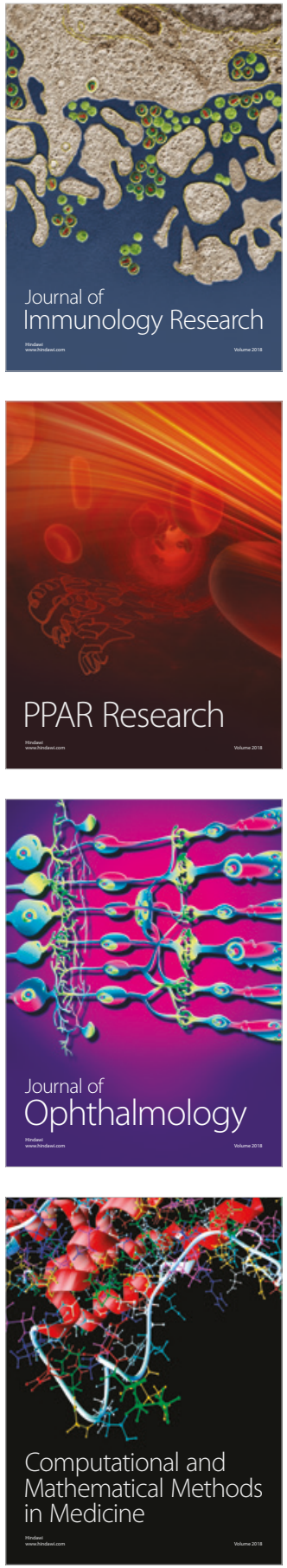

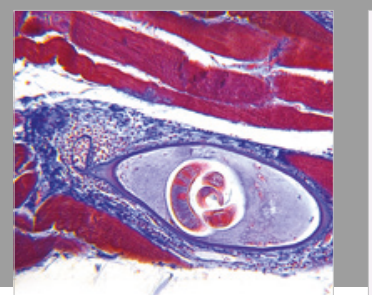

Gastroenterology Research and Practice



\section{Hindawi}

Submit your manuscripts at

www.hindawi.com
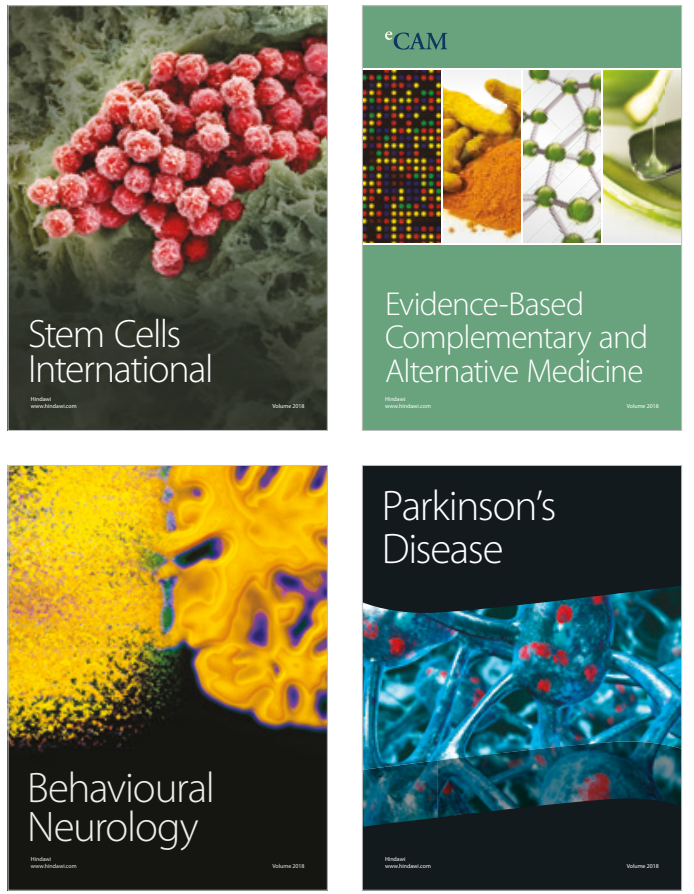

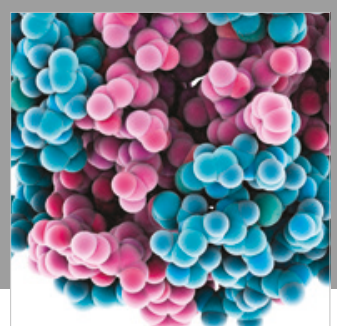

ournal of

Diabetes Research

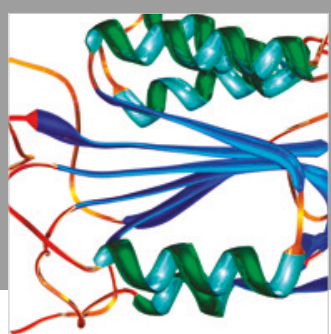

Disease Markers
